\title{
A novel class of piperidones exhibit potent, selective and pro-apoptotic anti-leukemia properties
}

\author{
LARISSA M NUNES $^{1 *}$, MOHAMMAD HOSSAIN $^{2 *}$, ARMANDO VARELA-RAMIREZ $^{1 *}$, UMASHANKAR DAS $^{2}$, \\ YOSHIRA M AYALA-MARIN ${ }^{1}$, JONATHAN R DIMMOCK ${ }^{2}$ and RENATO J AGUILERA ${ }^{1}$ \\ ${ }^{1}$ Cytometry, Imaging and Screening Core Facility, Border Biomedical Research Center, Department of Biological Sciences, \\ The University of Texas at El Paso, El Paso, TX 79968-0519, USA; ${ }^{2}$ Drug Discovery and Development Research Group, \\ College of Pharmacy and Nutrition, University of Saskatchewan, Saskatoon, SK S7N 5C9, Canada
}

Received May 26, 2015; Accepted December 15, 2015

DOI: $10.3892 / \mathrm{ol} .2016 .4480$

\begin{abstract}
In the present pre-clinical study, a series of 1-[3-(2-methoxyethylthio)-propionyl]-3,5- bis(benzylidene)-4 piperidones and structurally-related compounds were observed to be cytotoxic in vitro to three human leukemia cell lines, namely Nalm-6, CEM and Jurkat. The 50\% cytotoxic concentration $\left(\mathrm{CC}_{50}\right)$ values of the three cell lines ranged between $0.9-126.4 \mu \mathrm{M}$ and $0.3-11.7 \mu \mathrm{M}$ at 24 and $48 \mathrm{~h}$ subsequent to exposure, respectively. The two lead compounds with sub-micromolar $\mathrm{CC}_{50}$ concentrations, 1-(2-methoxyethylthio-propionyl)-3,5-bis(benzylidene)-4 piperidone (2a) and 3,5-bis(4-fluorobenzylidene)-1-[3-(2-methoxyethyl sulfinyl)-propionyl]-4-piperidone (3e), were selected for additional analyses. Several strategies were undertaken to determine whether the above piperidones caused cell death via apoptosis or necrosis on T-lymphocyte leukemia Jurkat cells. The results revealed that the two piperidones caused phosphatidylserine externalization, mitochondrial depolarization and activation of caspase-3, which are all biochemical hallmarks of apoptosis. In addition, the selected piperidones displayed selective cytotoxicity towards leukemia cells, and were less toxic in non-cancerous control cells. Therefore, the findings of the present study revealed that the novel piperidones $2 \mathrm{a}$ and $3 \mathrm{e}$ exert a selective cytotoxic effect on
\end{abstract}

Correspondence to: Dr Renato J Aguilera, Cytometry, Imaging and Screening Core Facility, Border Biomedical Research Center, Department of Biological Sciences, The University of Texas at El Paso, 500 West University Avenue, El Paso, TX 79968-0519, USA E-mail: raguilera@utep.edu

Dr Umashankar Das, Drug Discovery and Development Research Group, College of Pharmacy and Nutrition, University of Saskatchewan, 110 Science Place, Saskatoon, SK S7N 5C9, Canada E-mail: umashankar.das@usask.ca; umashankar.usask@gmail.com

*Contributed equally

Key words: apoptosis, leukemia, lymphoma, piperidone lymphocyte leukemia cells by favoring the activation of the intrinsic/mitochondrial apoptotic pathway.

\section{Introduction}

Leukemia, lymphoma and myeloma are a diverse category of malignant hematological neoplastic diseases that are initiated primarily in the blood, bone marrow and lymphoid organs. An estimated 52,380 newly diagnosed cases and 24,090 mortalities were associated with leukemia in 2014 (1). Non-Hodgkin lymphoma (NHL), the most common type of lymphoma, was diagnosed in 70,800 individuals, with 18,990 of them succumbing to the disease, in 2014 (1). Myeloma is the second most common type of blood cancer, with 24,050 novel cases and 11,090 mortalities reported in 2014 (1). In terms of prevalence, 917,086 patients with the above blood malignancies were living in 2014 in the USA, with NHL (530,919 patients) accounting for over half of these cases (1). According to the Leukemia and Lymphoma Society, approximately every $3 \mathrm{~min}, 1$ person is diagnosed with one of the aforementioned blood neoplasms in the USA $(1,2)$. However, identifying a cure for all the types of blood cancer is extremely challenging, as they are highly heterologous in nature and possess great genetic variability and diverse biochemical alterations $(1,3)$. Recently, several anti-lymphoma therapies have been developed that have improved the survival of patients with blood cancer, including novel chemotherapeutic agents and the use of combinatorial therapeutic strategies that combine cytotoxins with immune modulators such as monoclonal antibodies directed to specific receptors (4-8).

A major focus for numerous studies involves the synthesis and evaluation of novel anti-leukemic/lymphoma cytotoxins (9-16). The present study focuses on the development of conjugated unsaturated ketones or enones, which have a preferential or exclusive affinity for thiols, in contrast to amino or hydroxyl groups (17). Amino and hydroxyl substituents are present in nucleic acids. Therefore, the genotoxic problems associated with a number of current anticancer drugs may be avoided with the use of enones (18). In particular, the 1,5-diaryl-3-oxo-1,4-pentadienyl pharmacophore has been mounted on heterocyclic and cycloaliphatic scaffolds, and is considered to align at a primary binding site (19). The extent 
of this interaction may also be influenced by the nature of the groups placed on the piperidyl nitrogen atom (19). For example, the $\mathrm{N}$-acyl group may form additional bonds with various atoms and groups in cells, thus increasing the magnitude of the interaction at the primary binding site (19). A previous study revealed that the introduction of a 3-(2-hydroxyethylthio) propionyl group $\left(-\mathrm{COCH}_{2} \mathrm{CH}_{2} \mathrm{SCH}_{2} \mathrm{CH}_{2} \mathrm{OH}\right)$ on the piperidyl nitrogen atom led to a series of potent cytotoxins (20), whose general structure is represented in Fig. 1A. However, these compounds contain a terminal polar hydroxyl group that may be easily metabolized to acid analogs and impede cellular penetration (21). In the present study, the terminal polar hydroxyl group was masked by the corresponding methoxy analogue (Fig. 1B). In addition, the importance of the sulfur atom in the $\mathrm{N}$-acyl side chain, in association with cytotoxic potencies, was evaluated by replacing it with related groups. The structures of the resulting compounds are presented in Fig. 1C. The aim of the present study was to evaluate the cytotoxicity of novel 1-acyl-3,5-bis(benzylidene)-4-piperidones on a limited number of leukemia cell lines. The results demonstrate that the two most active piperidones investigated in the present study are able to induce apoptosis in the cell lines tested.

\section{Materials and methods}

Compounds for cytotoxic evaluations. The structures of the 12 compounds used in the present study are presented in Fig. $1 \mathrm{~B}$ and $\mathrm{C}$. The synthesis of these compounds was conducted at the College of Pharmacy and Nutrition, University of Saskatchewan (Saskatoon, Canada), details of which have recently been published (22). In brief, a similar methodology was used as described previously (20) in which aryl-aldehydes were condensed with 4-piperidone and the resultant product was acylated with a number of acyl chlorides to give the compounds in series 2 and 3 . The purified piperidones were characterized by proton nuclear magnetic resonance (NMR), carbon-13 NMR and organic elemental analysis of their carbon, hydrogen, nitrogen and sulfur content (results not shown) (22).

Cell lines and culture conditions. The human T-lymphocyte leukemia Jurkat (TIB-152; American Type Culture Collection, Manassas, VA, USA) (23), pre-B acute lymphoblastic leukemia Nalm-6 (ACC-128; DSMZ, Braunschweig, Germany) (24) and T lymphoblast acute lymphoblastic leukemia CCRF-CEM (American Type Culture Collection) (25) cell lines were grown in HyClone $^{\text {TM }}$ RPMI-1640 medium (GE Healthcare Life Sciences, Marlborough, MA, USA) supplemented with $10 \%$ heat-inactivated HyClone ${ }^{\mathrm{TM}}$ fetal bovine serum (FBS; GE Healthcare Life Sciences), $100 \mathrm{U} / \mathrm{ml}$ penicillin and $100 \mu \mathrm{g} / \mathrm{ml}$ streptomycin (15140-122; Thermo Fisher Scientific, Inc., Waltham, MA, USA). Human non-malignant epithelial mammary MCF-10A cells (CRL-10317; American Type Culture Collection) were grown in Dulbecco's Modified Eagle Medium/Nutrient Mixture F-12 Ham media (51445C; Sigma-Aldrich, St. Louis, MO, USA) supplemented with $10 \% \mathrm{FBS}, 10 \mu \mathrm{g} / \mathrm{ml}$ recombinant human insulin (Sigma-Aldrich), $20 \mathrm{ng} / \mathrm{ml}$ epidermal growth factor (Peprotech Inc., Rocky Hill, NJ, USA), $0.5 \mu \mathrm{g} / \mathrm{ml}$ hydrocortisone (Sigma-Aldrich), 2.5 mM L-glutamine (35050-061; Thermo Fisher Scientific, Inc.), $100 \mathrm{U} / \mathrm{ml}$ penicillin and $100 \mu \mathrm{g} / \mathrm{ml}$
A

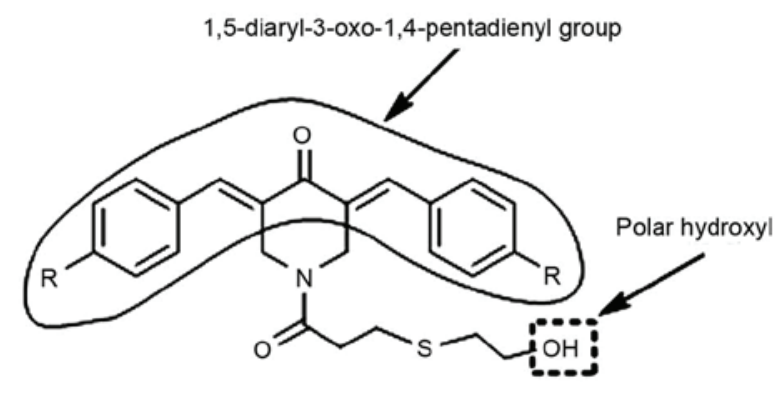

B<smiles>[R]c1ccc(/C=C2\CN(C(=O)CCSCCOC)C/C(=C\c3ccc([R])c([R])c3)C2=O)cc1[R]</smiles>

\begin{tabular}{l|ll} 
& $\mathrm{R}^{1}$ & $\mathrm{R}^{2}$ \\
\cline { 2 - 3 } $2 \mathrm{a}$ & $\mathrm{H}$ & $\mathrm{H}$ \\
$2 \mathrm{~b}$ & $\mathrm{NO}_{2}$ & $\mathrm{H}$ \\
$2 \mathrm{c}$ & $\mathrm{OCH}_{3}$ & $\mathrm{H}$ \\
$2 \mathrm{~d}$ & $\mathrm{~F}$ & $\mathrm{H}$ \\
$2 \mathrm{e}$ & $\mathrm{CH}_{3}$ & $\mathrm{H}$ \\
$2 \mathrm{f}$ & $\mathrm{OCH}_{3}$ & $\mathrm{OCH}_{3}$ \\
$2 \mathrm{~g}$ & $\mathrm{Cl}$ & $\mathrm{H}$
\end{tabular}

C<smiles>[X]CCCC(=O)N1C/C(=C\c2ccc([R])cc2)C(=O)/C(=C/c2ccc([R])cc2)C1</smiles>

\begin{tabular}{l|ll}
\hline $3 a$ & $\mathrm{R}^{1}$ & $\mathrm{X}$ \\
& $\mathrm{H}$ & $\mathrm{O}$ \\
$3 \mathrm{~b}$ & $\mathrm{H}$ & $\mathrm{SO}$ \\
$3 \mathrm{c}$ & $\mathrm{H}$ & $+\mathrm{S}_{\left(\mathrm{CH}_{3}\right) \mathrm{BF}_{4}^{-}}$ \\
$3 \mathrm{~d}$ & $\mathrm{H}$ & $\mathrm{SO}_{2}$ \\
$3 \mathrm{e}$ & $\mathrm{F}$ & $\mathrm{SO}$
\end{tabular}

Figure 1. (A) Structure of 1,5-diaryl-3-oxo-1,4-pentadienyl pharmacophore. Structures of the novel 1-[3-(2-methoxyethylthio)-propionyl]-3,5-bis(benzyl idene)-4 piperidones in (B) series 2 and (C) series 3 that contain conjugated unsaturated ketones or enones, in addition to the 1,5-diaryl-3-oxo-1,4-pentadienyl pharmacophore. The chemical names for compounds $2 \mathrm{a}$ and $3 \mathrm{e}$ are 1-(2-methoxyethylthio-propionyl)-3,5-bis(benzylidene)-4-piperidone and 3,5-bis(4-fluorobenzylidene)-1-[3-(2-methoxyethylsulfinyl)-propionyl]-4-piperidone, respectively. 
streptomycin. Nalm-6 and Jurkat cells were derived from male donors, whereas CEM and MCF-10A cells were derived from female donors (25). Cells that were growing at $60-75 \%$ confluence in the exponential growth phase were counted and seeded into 24- and 96-well plates (cat no. 167008; Thermo Fisher Scientific, Inc.) at a density of 100,000 and 10,000 cells/well in $1,000 \mu \mathrm{l}$ and $200 \mu \mathrm{l}$ culture medium, respectively. Cell incubation was performed at $37^{\circ} \mathrm{C}$ in a humidified atmosphere containing $5 \% \mathrm{CO}_{2}$. To procure high cell viability, the cells were prepared as previously described (26).

Differential nuclear staining (DNS) bioimaging assay. The cytotoxicity of the experimental compounds was tested on the various cell lines via live-cell DNS bioimaging assays (27). Cells in 96-well microplates, seeded as described above, were treated with various concentrations of experimental compounds (0.25-100 $\mu \mathrm{M})$ for 24 and $48 \mathrm{~h}$. A total of three controls were analyzed in each experimental plate, which included a compound solvent control [dimethyl sulfoxide (DMSO; D12345; Thermo Fisher Scientific, Inc.)]; cells treated with hydrogen peroxide $\left(\mathrm{H}_{2} \mathrm{O}_{2} ; 349887\right.$; Sigma-Aldrich) as a positive control for toxicity; and untreated cells to monitor the background of dead cells. To differentially label the cells, a mixture of two DNA-intercalating fluorescent dyes, consisting of $1 \mu \mathrm{g} / \mathrm{ml}$ Hoechst (H3570; Thermo Fisher Scientific, Inc.) and propidium iodide (PI; 0219545880; MP Biomedicals, Santa Ana, CA, USA), was added to each well $1 \mathrm{~h}$ prior to image recording (27). Hoechst stain is a blue fluorescent dye that may easily cross cell membranes of healthy and dead cells, and stains nuclear DNA, thus identifying the total number of cells (27). PI (red) only stains cells with compromised plasma membrane, thus indicating the number of dead cells (28). The fluorescence signals emitted by the stained cell nuclei were captured in two separate channels, in fulfillment with each individual fluorophore emission requirements (27). In order to capture acceptable numbers of regions of interest (equivalent to number of nuclei/cells), $2 \times 2$ image montages between four adjacent image fields were captured per well, using a 10x objective lens and a BD Pathway 855 Bioimaging System (BD Biosciences, San Jose, CA, USA). Image collection and data analysis that measured the percentage of dead cells in each individual experimental well was achieved using BD AttoVision version 1.6.2 software (BD Biosciences), and every test condition was assessed in quintuplicate. The $50 \%$ cytotoxic concentration $\left(\mathrm{CC}_{50}\right)$ was calculated using a linear interpolation equation with a gradient of concentrations, as previously described (29).

Apoptosis and necrosis assays. Disruption of phosphatidylserine (PS) membrane asymmetry, which is an early event of apoptotic cell death, was detected via flow cytometry upon treatment of cells with 1-(2-methoxyethylthio-propionyl)-3,5 -bis(benzylidene)-4 piperidone (2a) and 3,5-bis(4-fluorobenzy lidene)-1-[3-(2-methoxyethylsulfinyl)-propionyl]-4 piperidone (3e). Following incubation with the above compounds, cells were stained with fluorescein isothiocyanate (FITC)-labeled annexin V and PI (IM2375; Beckman Coulter, Inc., Miami, FL, USA), and monitored using flow cytometry (Cytomics FC 500 Flow Cytometer; Beckman Coulter, Inc.). Flow cytometry readily detects PS exposure on the external leaflet of the plasma membrane due to the high affinity of annexin for binding to PS on the cellular membrane (15). Jurkat cells seeded in 24-well plates were subsequently exposed to piperidones at their $\mathrm{CC}_{50}$ concentration $(1.4 \mu \mathrm{M})$ for $24 \mathrm{~h}$, and the treated cells were then harvested from each well in a pre-chilled ice-water cytometric tube (60818-437; VWR International, Houston, TX, USA), washed and processed as previously described (13). In each experimental plate, the following controls were included: Untreated cells; cells treated with compound solvent $(0.2 \%$ v/v DMSO); and cells exposed to $1 \mathrm{mM} \mathrm{H}_{2} \mathrm{O}_{2}$ as a positive control for cytotoxicity. The total percentage of apoptotic cells was determined by the addition of the annexin V-FITC ${ }^{+}$ early and late phases of apoptosis. Cells that stained only with PI, but not with annexin V-FITC, were considered to be the necrotic population. A total of $\sim 5,000$ individual cells/sample were collected and analyzed with CXP software version 2.2 (Beckman Coulter, Inc.).

Detection of mitochondrial membrane potential ( $\Delta \Psi m)$ disruption. Jurkat cells, seeded in a 24-well plates as described earlier, were exposed to $\mathrm{CC}_{50}$ concentrations of $2 \mathrm{a}$ and $3 \mathrm{e}$ for $6 \mathrm{~h}$, and labeled with $2 \mu \mathrm{M} 5,5$ ',6,6'-tetrachloro-1,1',3,3'-tetraethylbenzimidazolylcarbocyanine iodide (JC-1) fluorophore, following the manufacturer's protocol (MitoProbe ${ }^{\mathrm{TM}}$; Thermo Fisher Scientific, Inc.). Upon labeling with JC-1, cells with polarized mitochondria emitted a red fluorescence signal, while cells with depolarized mitochondria emitted a green fluorescence signal $(11,13)$. A flow cytometry protocol was used to monitor the percentage distribution profile of cells emitting red or green signals $(11,13)$. As a control for the dissipation of $\Delta \Psi \mathrm{m}, 1 \mathrm{mM} \mathrm{H} \mathrm{H}_{2}$ was utilized. In addition, a solvent control (1\% v/v DMSO) and untreated control cells were analyzed. Data collection and analysis was performed using CXP software.

Live-cell detection of caspase-3 activation. Jurkat cells were incubated for $6 \mathrm{~h}$ with $\mathrm{CC}_{50}$ concentrations of $2 \mathrm{a}$ and $3 \mathrm{e}$. Subsequently, caspase-3 activation was measured using the fluorogenic NucView ${ }^{\mathrm{TM}} 488$ Caspase-3/7 substrate for live cells, following the manufacturer's protocol (Biotium, Inc., Hayward, CA, USA). This caspase-3/7 substrate penetrates live cells with undamaged plasma membranes, and permits the identification of living cells with active caspase-3 (9). Cells exhibiting a green fluorescence signal, indicative of caspase-3 activation, were examined via flow cytometry (Cytomics FC 500 Flow Cytometer). The same positive and negative controls used in the preceding experiments were included and analyzed in the present series of experiments. CXP software was used for data acquisition and analysis.

Statistical analysis. Each data point was derived from $\leq 3$ replicates. Data are presented as the mean \pm standard deviation to determine experimental variability. Two-tailed paired Student's $t$-tests were performed to determine the statistical significance of differences among experimental samples and controls. $\mathrm{P}<0.01$ was considered to indicate a statistically significant difference for comparisons of two treatments.

\section{Results and Discussion}

Cytotoxicity examined by DNS assay. A well-established criterion that is used to define cell death is the irreversible 
Table I. $\mathrm{CC}_{50}{ }^{\mathrm{a}}$ values of experimental compounds upon exposure to human leukemia/lymphoma cells for 24 or $48 \mathrm{~h}$.

A, 24 h treatment

\begin{tabular}{|c|c|c|c|c|c|c|c|c|c|c|c|c|}
\hline Cell line & $2 \mathrm{a}$ & $2 b$ & $2 c$ & $2 d$ & $2 \mathrm{e}$ & $2 \mathrm{f}$ & $2 \mathrm{~g}$ & $3 a$ & $3 b$ & $3 c$ & $3 d$ & $3 e$ \\
\hline Nalm-6 & 1.80 & 23.80 & 79.07 & 5.20 & $-{ }^{b}$ & 46.60 & $-\mathrm{b}$ & 29.90 & 24.30 & 126.40 & 27.00 & 3.40 \\
\hline CEM & 0.90 & 2.70 & 45.20 & 25.10 & 99.40 & 52.50 & 5.80 & 5.20 & 3.10 & 21.50 & 3.10 & 2.90 \\
\hline Jurkat & 1.40 & 4.60 & 12.10 & 7.30 & 4.60 & 34.00 & 0.70 & 5.30 & 65.60 & 23.10 & 3.00 & 1.40 \\
\hline MCF-10A & $--^{c}$ & - & - & - & - & - & - & - & - & - & - & 14.80 \\
\hline
\end{tabular}

$\mathrm{B}, 48 \mathrm{~h}$ treatment

\begin{tabular}{lcccccccrrrrr}
\hline Cell line & $2 \mathrm{a}$ & $2 \mathrm{~b}$ & $2 \mathrm{c}$ & $2 \mathrm{~d}$ & $2 \mathrm{e}$ & $2 \mathrm{f}$ & $2 \mathrm{~g}$ & $3 \mathrm{a}$ & $3 \mathrm{~b}$ & $3 \mathrm{c}$ & $3 \mathrm{~d}$ & $3 \mathrm{e}$ \\
\hline Nalm-6 & 0.90 & 1.50 & 6.20 & 0.90 & 3.60 & 10.70 & 0.50 & 10.60 & 7.00 & 10.50 & 11.70 & 0.50 \\
CEM & 0.60 & 0.60 & 6.30 & 2.00 & 3.20 & 5.00 & 1.30 & 1.40 & 1.50 & 6.30 & 1.30 & 0.30 \\
Jurkat & 0.50 & 0.30 & 5.60 & 1.50 & 1.70 & 8.00 & 0.80 & 1.50 & 2.00 & 3.40 & 0.40 & 0.60 \\
MCF-10A & $-\mathrm{c}$ & - & - & - & - & - & - & - & - & - & - & 3.90
\end{tabular}

${ }^{\mathrm{a}} \mathrm{CC}_{50}$ values are presented in $\mu \mathrm{M}$ units. Missing data are marked by.- The $\mathrm{CC}_{50}$ is defined as the concentration of drug required to disrupt the plasma membrane integrity of $50 \%$ of the cell population following $24 \mathrm{~h}$ and $48 \mathrm{~h}$ of incubation, as compared with DMSO-treated cells. Cells with a compromised plasma membrane were quantified using propidium iodide via differential nuclear staining assay. All compounds were dissolved in DMSO. ${ }^{b}$ The $\mathrm{CC}_{50}$ was not calculated for $2 \mathrm{e}$ and $2 \mathrm{~g}$ in Nalm- 6 cells at $24 \mathrm{~h}$, since their toxicity was $<30 \%$ at the maximum soluble concentration of the compounds tested. ${ }^{\mathrm{C}}$ In MCF-10A cells, $<15 \%$ cytotoxicity was detected at the maximum concentration of soluble compound tested ( $8 \mu \mathrm{M}$ for $2 \mathrm{a}$ and $3 \mathrm{e})$. $\mathrm{CC}_{50}, 50 \%$ cytotoxic concentration; DMSO, dimethyl sulfoxide.

disruption of the plasma membrane, which may be easily visualized with PI fluorescent dye that specifically enters dead or dying cells (11). In the present study, PI was employed to quantify the cytotoxicity of all the experimental compounds tested on various cell lines using the live-cell DNS assay (27). As indicated in Table I, a wide disparity in the cytotoxic potency of the compounds was observed in series 2 and 3 at the two time points tested. At $24 \mathrm{~h}$, the $2 \mathrm{a}$ and $3 \mathrm{e} \mathrm{CC}_{50}$ values for the three malignant cell lines ranged between 0.9 and $1.8 \mu \mathrm{M}$, and between 1.4 and $3.4 \mu \mathrm{M}$, respectively. In addition, $48 \mathrm{~h}$ subsequent to treatment, only $2 \mathrm{a}$ and $3 \mathrm{e}$ exhibited consistent sub-micromolar $\mathrm{CC}_{50}$ values for all the malignant cells tested, with values ranging between 0.5 and $0.9 \mu \mathrm{M}$, and between 0.3 and $0.6 \mu \mathrm{M}$, respectively. The most potent compound in series 2 was the unsubstituted analogue $2 \mathrm{a}$. Therefore, in series 2 , substituents in the aryl rings may decrease the cytotoxic potencies. Analysis of the toxicity of compounds in series 3a-d revealed that replacement of the sulfur atom of $2 \mathrm{a}$ with other groups led to an increase in $\mathrm{CC}_{50}$ values, and resulted in less toxic compounds. Subsequent to incubation of the various cell lines with piperidones for $48 \mathrm{~h}$, the unsubstituted compound in series 2 and the 2 analogues that contained strongly-withdrawing substituents ( $2 \mathrm{~b}$ and $2 \mathrm{~g}$ ), exhibited $\mathrm{CC}_{50}$ values in the sub-micromolar range. In series 3 , the most potent piperidone was $3 \mathrm{e}$, with a $\mathrm{CC}_{50}$ value that ranged between 0.3 and $0.6 \mu \mathrm{M}$ subsequent to $48 \mathrm{~h}$ incubation. A comparison of the various sensitivities of the cell lines to the compounds in series 2 and 3 was performed. The combined $\mathrm{CC}_{50}$ values of series 2 and 3 compounds subsequent to $24 \mathrm{~h}$ incubation on Nalm-6, CEM and Jurkat cells ranged between 1.8-126.4, 0.9-99.4 and 0.7-65.6 $\mu \mathrm{M}$, respectively. Subsequent to $48 \mathrm{~h}$ incubation, the $\mathrm{CC}_{50}$ values ranged between $0.9-11.7$, 0.6-6.3 and 0.3-5.6 $\mu \mathrm{M}$, respectively. These assays revealed that the most potent and promising compounds were $2 \mathrm{a}$ and 3 e. These piperidones were additionally tested on the human non-cancerous MCF-10A cell line. As shown in Table I, 2a possessed decreased cytotoxic activity $(<15 \%)$ at the highest concentration used $(8 \mu \mathrm{M})$, following 24 and $48 \mathrm{~h}$ incubation with the non-cancerous cells. Notably, the $\mathrm{CC}_{50}$ values were not determined for cells with decreased cytotoxicity, as $2 \mathrm{a}$ was not soluble at high concentrations. The cytotoxicity of $3 \mathrm{e}$ was 10.6 (24 h) and 6.5 (48 h)-fold higher in the T-lymphocyte leukemia cells than in the non-malignant cells (Table I). Varying degrees of $3 \mathrm{e}$ selective cytotoxicity were also observed on Nalm-6 and CEM cells (Table I). However, 2a exhibited $<15 \%$ cytotoxicity towards the non-cancerous cell line at 24 and $48 \mathrm{~h}$ at the highest soluble concentration tested $(8 \mu \mathrm{M})$. Furthermore, $2 \mathrm{a}$ also demonstrated selective toxicity towards leukemia cells (Table I). These findings demonstrate that the piperidone analogues $2 \mathrm{a}$ and $3 \mathrm{e}$ possessed selective cytotoxicity towards the three leukemia cell lines tested at sub-micromolar concentrations.

Cell death analysis by PS externalization. Apoptosis and necrosis are the two major modes of cell death, and PS externalization is a biochemical event that distinguishes between the two (30). PS is an aminophospholipid that is predominantly confined in the inner leaflet of the plasma membrane of resting cells (31). The presence of PS at the surface of cells is indicative of the loss of phospholipid membrane asymmetry, and is also a distinctive event of apoptosis (32). Assays that detect PS externalization are centered on the high-affinity 


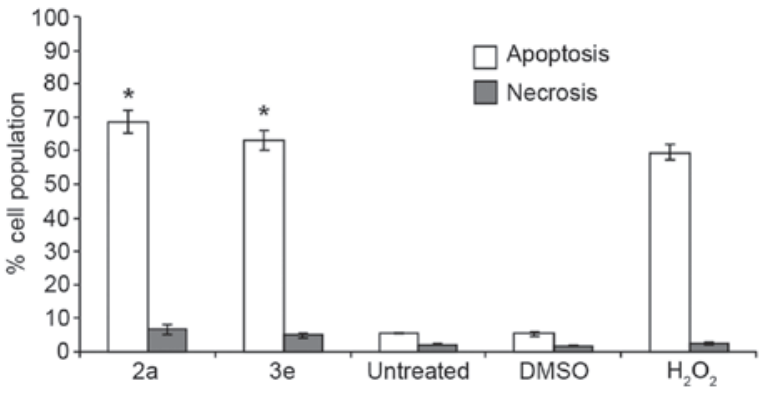

Figure 2. Exposure of Jurkat cells to compounds 2a and $3 \mathrm{e}$ results in phosphatidylserine externalization. The cell death mechanism (apoptosis or necrosis) was monitored via flow cytometry upon co-staining the cells with annexin V-FITC and PI. Cells were exposed for $48 \mathrm{~h}$ to $2 \mathrm{a}$ and $3 \mathrm{e}$ at their $50 \%$ cytotoxic concentration $(1.4 \mu \mathrm{M}$, as determined at $24 \mathrm{~h})$. The total percentage of apoptotic (annexin V-FITC ${ }^{+}$) Jurkat cells is expressed as the sum of percentages of cells at the early and late stages of apoptosis (open bars). Cells that were stained only with PI due to their compromised plasma membrane integrity, but which did not exhibit FITC signal, are considered to be necrotic cells (grey bars). Each bar represents the mean \pm standard deviation of 3 independent replicates. The following controls were included: Untreated cells, as a negative control; cells treated with $0.2 \% \mathrm{v} / \mathrm{v}$ dimethyl sulfoxide, as a control for solvent effects; and cells exposed to $1 \mathrm{mM} \mathrm{H}_{2} \mathrm{O}_{2}$, as a positive control. Statistically significant differences between cells treated with compounds and solvent-treated control cells are denoted by asterisks ( $\mathrm{P}<0.0001)$, and were analyzed using the two-tailed Student's $t$-test. FITC, fluorescein isothiocyanate; PI, propidium iodide; DMSO, dimethyl sulfoxide; $\mathrm{H}_{2} \mathrm{O}_{2}$, hydrogen peroxide.

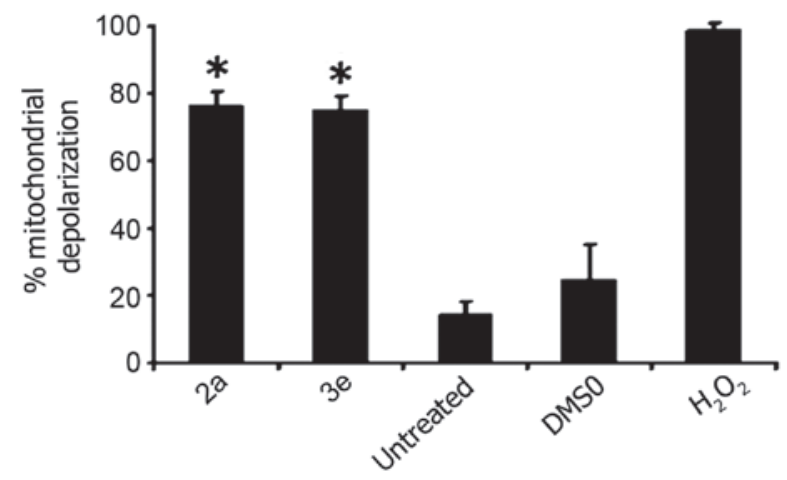

Figure 3. Cytotoxicity mediated by $2 \mathrm{a}$ and $3 \mathrm{e}$ is dependent of $\Delta \Psi \mathrm{m}$ disruption in Jurkat cells. Cells were exposed for $6 \mathrm{~h}$ to $2 \mathrm{a}$ and $3 \mathrm{e}$ at their $50 \%$ cytotoxic concentration $(1.4 \mu \mathrm{M}$, as determined at $24 \mathrm{~h})$. Variations in the $\Delta \Psi \mathrm{m}$ were detected by staining the cells with the aggregate-forming lipophilic cationic fluorophore 5,5',6,6'-tetrachloro-1,1',3,3'-tetraethylbenzimidazolylcarbocyanine iodide $(2 \mu \mathrm{M})$, and monitored via flow cytometry. Percentages of cells emitting green fluorescence signal (indicative of mitochondrial depolarization) are depicted on the y axis. Each bar represents the mean \pm standard deviation of 4 independent replicates. For the assays, three controls were included: Untreated cells; cells treated with $0.1 \% \mathrm{v} / \mathrm{v}$ dimethyl sulfoxide; and cells exposed to $1 \mathrm{mM} \mathrm{H}_{2} \mathrm{O}_{2}$. Statistically significant differences between cells treated with compounds and solvent-treated control cells are denoted by asterisks ( $\mathrm{P}<0.0001)$, and were analyzed using the two-tailed Student's $t$-test. For each sample, $\sim 10,000$ cells were acquired and analyzed using CXP software. $\Delta \Psi \mathrm{m}$, mitochondrial membrane potential; DMSO, dimethyl sulfoxide; $\mathrm{H}_{2} \mathrm{O}_{2}$, hydrogen peroxide.

binding of annexin V to PS (11). FITC-labeled annexin V, a $36 \mathrm{kDa} \mathrm{Ca}{ }^{2+}$-dependent PS-binding protein, may readily identify the event (33). The compounds with the lowest $\mathrm{CC}_{50}$ across all cell lines were $2 \mathrm{a}$ and $3 \mathrm{e}$ (Table I). Therefore, the $2 \mathrm{a}$ and $3 \mathrm{e}$ piperidones were used to elucidate the mechanism of cell death induction on T-lymphocyte leukemia cells. The

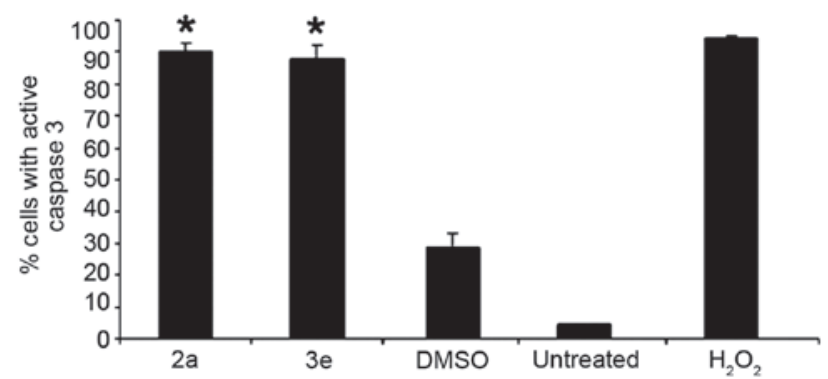

Figure 4. Piperidones $2 \mathrm{a}$ and $3 \mathrm{e}$ elicited caspase-3 activation in T-lymphocyte leukemia Jurkat cells. Cells were exposed for $6 \mathrm{~h}$ to $50 \%$ cytotoxic concentration of $2 \mathrm{a}$ and $3 \mathrm{e}(1.4 \mu \mathrm{M}$, as determined at $24 \mathrm{~h})$. Percentages of cells with active caspase-3, which exhibit a green fluorescence signal, are indicated on the y axis. Cells were subjected to different treatments, as indicated on the $\mathrm{x}$ axis. Each bar represents the mean value of 3 independent measurements, and the error bars represent the standard deviation. Statistically significant differences between cells treated with compounds and solvent-treated control cells are denoted by asterisks $\left({ }^{*} \mathrm{P}<0.0001\right)$, and were analyzed using the two-tailed Student's $t$-test. In total, 5,000 cells/sample were collected and analyzed using CXP software. DMSO, dimethyl sulfoxide; $\mathrm{H}_{2} \mathrm{O}_{2}$, hydrogen peroxide.

detection of PS exposure on the external leaflet of the cellular membrane was examined by flow cytometry using a live-cells mode protocol. Jurkat cells were individually exposed for $48 \mathrm{~h}$ to the $\mathrm{CC}_{50}$ values of $2 \mathrm{a}$ and $3 \mathrm{e}$ determined at $24 \mathrm{~h}(1.4 \mu \mathrm{M}$; Table I). As shown in Fig. 2, PS externalization was clearly detected subsequent to $48 \mathrm{~h}$ of exposure to $2 \mathrm{a}$ and $3 \mathrm{e}(29,34)$. Cells treated with $2 \mathrm{a}$ or $3 \mathrm{e}$ exhibited significantly increased $(>60 \%)$ numbers of annexin V-FITC ${ }^{+}$cells, compared with the solvent controls $(\mathrm{P}<0.0001 ;$ Fig. 2). Notably, 2a and 3e induced increased PS externalization, similarly to the positive control used in the present study $\left(1 \mathrm{mM} \mathrm{H}_{2} \mathrm{O}_{2}\right.$; Fig. 2). These findings suggest that compounds $2 \mathrm{a}$ and $3 \mathrm{e}$ are likely to induce cell death via apoptosis rather than necrosis.

$\Delta \Psi m$ status of treated cells. Apoptosis may be initiated via the intrinsic or the extrinsic pathway (34-36). The intrinsic pathway is generally characterized by a perturbation of the mitochondrial function, whereas the extrinsic pathway is activated by membrane death receptor signaling (35). In order to gain additional insight into the succession of events induced by $2 \mathrm{a}$ and $3 \mathrm{e}, \Delta \Psi \mathrm{m}$ integrity was examined at an early incubation time point $(6 \mathrm{~h})$. The mitochondrion is the principal energy-producing organelle in animals, and is considered to be important in cell survival and death (36). The stimulus that elicits the dissipation of the $\Delta \Psi \mathrm{m}$ is an initial distinctive biochemical feature of the intrinsic apoptosis pathway (37). The loss of $\Delta \Psi \mathrm{m}$ provokes the release of downstream pro-apoptotic proteins into the cytosol, consequently activating several apoptotic effectors such as caspase-3 (37). Additionally, impaired mitochondrial function may negatively impact cellular energy levels leading to ATP depletion and cell death (36). At present, there are several approved anticancer agents that induce apoptotic cell death by disrupting the $\Delta \Psi \mathrm{m}$, including etoposide, doxorubicin and 1- $\beta$-D-arabinofuranosyl cytosine (38). To determine the initial signal utilized by $2 \mathrm{a}$ and 3e to activate cytotoxicity in T-lymphocyte leukemia Jurkat cells, the JC-1 reagent was utilized to detect changes in the $\Delta \Psi \mathrm{m}$ (39). As shown in Fig. 3, the majority of Jurkat cells 
$(>75 \%)$ exhibited a green fluorescence signal following $6 \mathrm{~h}$ of exposure to $2 \mathrm{a}$ and $3 \mathrm{e}$, which is indicative of the dissipation of the $\Delta \Psi \mathrm{m}$. The strong $\Delta \Psi_{\mathrm{m}}$ perturbation mediated by $2 \mathrm{a}$ and $3 \mathrm{e}$ indicates that these compounds induced the intrinsic apoptotic pathway as a mechanism that elicits cell death (Fig. 3).

Live-cell detection of intracellular caspase-3 activation. Caspase-3, the major downstream apoptotic executioner enzyme, is involved in the most destructive phases of apoptosis $(40,41)$. Also, caspase-3 activation is a well-known biochemical marker of apoptosis (40). In the present study, the activation of caspase- 3 in living cells was analyzed via flow cytometry, using the fluorogenic enzyme substrate NucView $^{\mathrm{TM}} 488$ Caspase-3/7. This substrate contains the tetrapeptide sequence DEVD, which corresponds to the cleavage site by active caspase- 3 present in poly(adenosine diphosphate-ribose) polymerase-1. Using flow cytometry, $2 \mathrm{a}$ and $3 \mathrm{e}$ were observed to induce the conversion of pro-caspase- 3 to active caspase-3, following $6 \mathrm{~h}$ of treatment in Jurkat cells (Fig. 4). A significant ( $>85 \% ; \mathrm{P}<0.0001)$ induction of caspase-3 activity was detected at $\mathrm{CC}_{50}$ concentrations of $2 \mathrm{a}$ and $3 \mathrm{e}$, compared with DMSO-treated and untreated cells (Fig. 4). These results indicate that $2 \mathrm{a}$ and $3 \mathrm{e}$ induced apoptosis via caspase- 3 activation, and are in agreement with the findings of the present study, which indicated that $2 \mathrm{a}$ and $3 \mathrm{e}$ induced PS externalization and mitochondrial depolarization. Therefore, $2 \mathrm{a}$ and $3 \mathrm{e}$ appear to activate early and middle biochemical facets of the apoptosis cascade.

Conclusion. The present study revealed that two novel piperidones, $2 \mathrm{a}$ and $3 \mathrm{e}$, exert potent and selective cytotoxicity towards human leukemia Nalm-6, CEM and Jurkat cells. Additionally, the T-lymphocyte leukemia Jurkat cell line exhibited increased sensitivity to the two compounds subsequent to 24 and $48 \mathrm{~h}$ of exposure. Examination of the cell death mechanism that was involved in the observed cytotoxicity revealed that $2 \mathrm{a}$ and $3 \mathrm{e}$ elicited PS externalization, depolarization of the mitochondrial membrane potential and activation of caspase-3 on Jurkat cells. A key result of the present study is that the novel $2 \mathrm{a}$ and $3 \mathrm{e}$ piperidones are promising experimental anti-leukemia cytotoxins. The piperidones primarily inflict programmed cell death in human T-lymphocyte leukemic cells via the intrinsic/mitochondrial/caspase-3 apoptotic pathway, which indicates that additional studies regarding these compounds are required. Future studies on the drugs discussed in the present study may include the development of novel piperidone-derived analogues based on the structure of the aforementioned two lead compounds, with the aim of improving potency and selective cytotoxicity against malignant cells in anti-cancer drug design strategies.

\section{Acknowledgements}

Funding for the present study was provided by the National Institute of General Medical Sciences Support of Competitive Research [(a component of the National Institutes of Health (NIH); Bethesda, MD, USA] (grant no. 1SC3GM103713-03), the Canadian Institutes of Health Research (Ottawa, ON, Canada) and the Saskatchewan Health Research Foundation (Saskatoon, SK, Canada). The authors would like to thank
Ms. Gladys Almodovar for the critical review of the manuscript and cell culture expertise, and the staff members of the Cytometry, Screening and Imaging Core Facility of the Border Biomedical Research Center at The University of Texas at El Paso (El Paso, TX, USA), which was supported by the National Institute on Minority Health and Health Disparities (a component of the NIH) via the Research Center in Minority Institutions program (grant no. 5G12MD007592-22). Mrs. Yoshira M. Ayala-Marin was supported by the National Institutes of General Medical Sciences Research Initiative for Scientific Enhancement grant (no. R25GM069621-12).

\section{References}

1. Howlader N, Noone AM, Krapcho M, Garshell J, Miller D, Altekruse SF, Kosary CL, Yu M, Ruhl J, Tatalovich Z, et al (eds). SEER Cancer Statistics Review, 1975-2011. National Cancer Institute. Surveillance, Epidemiology, and End Results Program. National Institutes of Health, Bethesda, MD, USA, 2013. http://seer.cancer.gov/csr/1975_2012. Accessed, February 2016.

2. American Cancer Society. Cancer Infographics Gallery. Atlanta, GA, USA, 2015. www.cancer.org/infographics. Accessed, March 2016.

3. Inklekofer AM and Younes A: Precision therapy for lymphoma - current state and future directions. Nat Rev Clin Oncol 11: 585-596, 2014.

4. Diaz T, Navarro A, Ferrer G, Gel B, Gaya A, Artells R, Bellosillo B, Garcia-Garcia M, Serrano S, Martínez A and Monzo M: Lestaurtinib inhibition of the Jak/STAT signaling pathway in hodgkin lymphoma inhibits proliferation and induces apoptosis. PLoS One 6: e18856, 2011.

5. Hart S, Goh KC, Novotny-Diermayr V, Hu CY, Hentze H, Tan YC, Madan B, Amalini C, Loh YK, Ong LC, et al: SB1518, a novel macrocyclic pyrimidine-based JAK2 inhibitor for the treatment of myeloid and lymphoid malignancies. Leukemia 25: 1751-1759, 2011.

6. Burington B, Yue P, Shi X, Advani R, Lau JT, Tan J, Stinson S, Stinson J, Januario T, de Vos S, et al: CD40 pathway activation status predicts response to CD40 therapy in diffuse large B cell lymphoma. Sci Transl Med 3: 74ra22, 2011.

7. Arrondeau J, Gan HK, Razak AR, Paoletti X and Le Tourneau C: Development of anti-cancer drugs. Discov Med 10: 355-362, 2010.

8. Masood A, Sher T, Paulus A, Miller KC, Chitta KS and Chanan-Khan A: Targeted treatment for chronic lymphocytic leukemia. Onco Targets Ther 4: 169-183, 2011.

9. Pedroza DA, De Leon F, Varela-Ramirez A, Lema C Aguilera RJ and Mito S: The cytotoxic effect of 2-acylated-1,4-naphthohydroquinones on leukemia/lymphoma cells. Bioorg Med Chem 22: 842-847, 2014.

10. Martínez A, Carreon T, Iniguez E, Anzellotti A, Sánchez A, Tyan M, Sattler A, Herrera L, Maldonado RA and Sánchez-Delgado RA: Searching for new chemotherapies for tropical diseases: Ruthenium-clotrimazole complexes display high in vitro activity against Leishmania major and Trypanosoma cruzi and low toxicity toward normal mammalian cells. J Med Chem 55: 3867-3877, 2012.

11. Robles-Escajeda E,Lerma D, Nyakeriga AM,Ross JA, KirkenRA, Aguilera RJ and Varela-Ramirez A: Searching in mother nature for anti-cancer activity: Anti-proliferative and pro-apoptotic effect elicited by green barley on leukemia/lymphoma cells. PLoS One 8: e73508, 2013.

12. Martínez A, Rajapakse CS, Sánchez-Delgado RA, Varela-Ramirez A, Lema C and Aguilera RJ: Arene-Ru(II)-chloroquine complexes interact with DNA, induce apoptosis on human lymphoid cell lines and display low toxicity to normal mammalian cells. J Inorg Biochem 104: 967-977, 2010.

13. Robles-Escajeda E, Martínez A, Varela-Ramirez A, Sánchez-Delgado RA and Aguilera RJ: Analysis of the cytotoxic effects of ruthenium-ketoconazole and ruthenium-clotrimazole complexes on cancer cells. Cell Biol Toxicol 29: 431-443, 2013.

14. Elie BT, Levine C, Ubarretxena-Belandia I, Varela-Ramírez A, Aguilera RJ, Ovalle R and Contel $\mathrm{M}$ : Water soluble phosphane-gold(I) complexes. Applications as recyclable catalysts in a three-component coupling reaction and as antimicrobial and anticancer agents. Eur J Inorg Chem 2009: 3421-3430, 2009. 
15. Shaik N, Martínez A, Augustin I, Giovinazzo H, Varela-Ramírez A, Sanaú M, Aguilera RJ and Contel M: Synthesis of apoptosis-inducing iminophosphorane organogold(III) complexes and study of their interactions with biomolecular targets. Inorg Chem 48: 1577-1587, 2009.

16. Santiago-Vazquez Y, Das S, Das U, Robles-Escajeda E, Ortega NM, Lema C, Varela-Ramírez A, Aguilera RJ, Balzarini J, De Clercq E, et al: Novel 3,5-bis(arylidene)-4-oxo-1-piperidinyl dimers: Structure-activity relationships and potent antileukemic and antilymphoma cytotoxicity. Eur J Med Chem 77: 315-322, 2014

17. Pati HN, Das U, Sharma RK and Dimmock JR: Cytotoxic thiol alkylators. Mini Rev Med Chem 7: 131-139, 2007.

18. Chen EX and Moore MJ: In: Principles of Medical Pharmacology. Kalant H, Grant DM and Mitchell J (eds). 7th edition. Saunders-Elsevier, Toronto, Canada, p778, 2007.

19. Das U, Sharma RK and Dimmock JR: 1,5-diaryl-3-oxo-1,4pentadienes: A case for antineoplastics with multiple targets. Curr Med Chem 16: 2001-2020, 2009.

20. Das U,PatiHN, Sakagami H,Hashimoto K, Kawase M,Balzarini J, De Clercq E and Dimmock JR: 3,5-Bis(benzylidene)-1-[3-(2hydroxyethylthio)propanoyl]piperidin-4-ones: A novel cluster of potent tumor-selective cytotoxins. J Med Chem 54: 3445-3449, 2011.

21. Pandeya SN and Dimmock JR (eds): Chemical parameters in drug design. In: An Introduction to Drug Design. New Age International, New Delhi, India, p90, 1997.

22. Hossain M, Das U, Umemura N, Sakagami H, Balzarini J, De Clercq E, Kawase M and Dimmock JR: Tumour-specific cytotoxicity and structure-activity relationships of novel 1-[3-(2-methoxyethylthio)propionyl]-3,5-bis(benzylidene)-4-pip eridones. Bioorg Med Chem (In press).

23. Schneider U, Schwenk HU and Bornkamm G: Characterization of EBV-genome negative 'null' and ' $T$ ' cell lines derived from children with acute lymphoblastic leukemia and leukemic transformed non-Hodgkin lymphoma. Int J Cancer 19: 621-626, 1977.

24. Hurwitz R, Hozier J, LeBien T, Minowada J, Gajl-Peczalska K, Kubonishi I and Kersey J: Characterization of a leukemic cell line of the pre-B phenotype. Int J Cancer 23:174-180, 1979.

25. Foley GE, Lazarus H, Farber S, Uzman BG, Boone BA and McCarthy RE: Continuous culture of human lymphoblasts from peripheral blood of a child with acute leukemia. Cancer 18: $522-529,1965$

26. Nunes LM, Robles-Escajeda E, Santiago-Vazquez Y, Ortega NM, Lema C, Muro A, Almodovar G, Das U, Das S, Dimmock JR, et al: The gender of cell lines matters when screening for novel anti-cancer drugs. AAPS J 16: 872-874, 2014

27. Lema C, Varela-Ramirez A and Aguilera RJ: Differential nuclear staining assay for high-throughput screening to identify cytotoxic compounds. Curr Cell Biochem 1: 1-14, 2011.
28. Robles-Escajeda E, Das U, Ortega NM, Parra K, Francia G, Dimmock JR, Varela-Ramirez A and Aguilera RJ: A novel curcumin-like dienone induces apoptosis in triple-negative breast cancer cells. Cell Oncol: Feb 26, 2016 (Epub ahead of print).

29. Varela-Ramirez A, Costanzo M, Carrasco YP, Pannell KH and Aguilera RJ: Cytotoxic effects of two organotin compounds and their mode of inflicting cell death on four mammalian cancer cells. Cell Biol Toxicol 27: 159-168, 2011.

30. Fadok VA, de Cathelineau A, Daleke DL, Henson PM and Bratton DL: Loss of phospholipid asymmetry and surface exposure of phosphatidylserine is required for phagocytosis of apoptotic cells by macrophages and fibroblasts. J Biol Chem 276: 1071-1077, 2001

31. Williamson P and Schlegel RA: Back and forth: The regulation and function of transbilayer phospholipid movement in eukaryotic cells. Mol Membr Biol 11: 199-216, 1994.

32. Soares MM, King SW and Thorpe PE: Targeting inside-out phosphatidylserine as a therapeutic strategy for viral diseases. Nat Med 14: 1357-1362, 2008.

33. Boersma HH, Kietselaer BL, Stolk LM, Bennaghmouch A, Hofstra L, Narula J, Heidendal GA and Reutelingsperger CP: Past, present, and future of annexin A5: From protein discovery to clinical applications. J Nucl Med 46: 2035-2050, 2005.

34. Fadok VA, Voelker DR, Campbell PA, Cohen JJ, Bratton DL and Henson PM: Exposure of phosphatidylserine on the surface of apoptotic lymphocytes triggers specific recognition and removal by macrophages. J Immunol 148: 2207-2216, 1992.

35. Lavrik I, Golks A and Krammer PH: Death receptor signaling. J Cell Sci 118: 265-267, 2005.

36. Danial NN and Korsmeyer SJ: Cell death: Critical control points. Cell 116: 205-219, 2004

37. Saelens X, Festjens N, Vande Walle L, van Gurp M, van Loo G and Vandenabeele P: Toxic proteins released from mitochondria in cell death. Oncogene 23: 2861-2874, 2004.

38. Tang L, Boise LH, Dent P and Grant S: Potentiation of 1-beta-D-arabinofuranosylcytosine-mediated mitochondrial damage and apoptosis in human leukemia cells (U937) overexpressing bcl-2 by the kinase inhibitor 7-hydroxystaurosporine (UCN-01). Biochem Pharmacol 60: 1445-1456, 2000.

39. Petit PX, Lecoeur H, Zorn E, Dauguet C, Mignotte B and Gougeon ML: Alterations in mitochondrial structure and function are early events of dexamethasone-induced thymocyte apoptosis. J Cell Biol 130: 157-167, 1995.

40. Degterev A, Boyce M and Yuan J: A decade of caspases. Oncogene 22: 8543-8567, 2003.

41. Solary E, Droin N, Bettaieb A, Corcos L, Dimanche-Boitrel MT and Garrido C: Positive and negative regulation of apoptotic pathways by cytotoxic agents in hematological malignancies. Leukemia 14: 1833-1849, 2000. 